\title{
Undervalued Impacts of Sea-Level Rise: Vanishing Deltas
}

\author{
Teresa Vegas-Vilarrúbia ${ }^{1 *}$ and Valentí Rull ${ }^{2}$ \\ ${ }^{1}$ Department of Evolutive Biology, Ecology and Environmental Sciences of the University of Barcelona, Barcelona, Spain, \\ ${ }^{2}$ Institute of Earth Sciences Jaume Almera, Spanish National Research Council, Barcelona, Spain
}

Keywords: adaptation, climate change, conservation figures, biodiversity loss, megadeltas, human migration

OPEN ACCESS

Edited by:

Ralf Christopher Buckley,

Griffith University, Australia

Reviewed by:

Sebastian Villasante,

Universidade de Santiago de

Compostela, Spain

*Correspondence:

Teresa Vegas-Vilarrúbia tvegas@ub.edu

Specialty section:

This article was submitted to

Conservation,

a section of the journal

Frontiers in Ecology and Evolution

Received: 04 February 2016

Accepted: 09 June 2016

Published: 23 June 2016

Citation:

Vegas-Vilarrúbia T and Rull V (2016) Undervalued Impacts of Sea-Level

Rise: Vanishing Deltas.

Front. Ecol. Evol. 4:77.

doi: 10.3389/fevo.2016.00077
Located in the transition between the continent and ocean, most deltas are strongholds of biodiversity. They encompass marshes, islands, tidal channels, and lakes, as well as mosaics of forests, grasslands, and dunes in the wetland area, thus providing a large variety of habitats, ecosystem goods, and services. Most deltas have experienced intense transformations with significant loss of biodiversity due to direct human activities (Syvitski et al., 2009). Many major deltas harbor a fast growing population (Supplementary Figure 1) and are important economic hubs with intense urbanization, industrialization, and agriculture. In recent decades, deltas have been threatened by sea-level rise (SLR), which, in combination with subsidence and/or extreme meteorological events (cyclones, storm surges), places the ecosystems and human populations at risk (Schneider et al., 2007). In the twentieth century, the global mean sea level increased by $0.19 \mathrm{~m}$, and the forecasts for the twenty-first century foresee an increase of $0.26-0.98 \mathrm{~m}$, provided that no changes in ocean mass or volume occur and no regional factors such as ocean circulation or sediment transport arise. Many deltaic or delta-dependent habitats are expected to profoundly change or disappear from now until 2100, and human and deltaic ecosystems will become progressively more exposed to SLR because of the landward transgression of seawater (Church et al., 2013; IPCC, 2013). There are initiatives to protect or save deltas from drowning, but the involved actions (e.g., rebuilding, restoring, channelization) are expensive and only offer generic solutions because of crucial knowledge gaps (Giosan et al., 2014). In this paper, we warn against the possibility that many deltas will disappear as a result of the near-future SLR and emphasize that, even without knowing when, where and how this will occur, we can take conceptually simple steps to decrease the impacts on deltaic diversity and human beings by applying common sense and extending the time horizon of our predictions.

There is growing concern that SLR, exacerbated by human impact, will destroy the majority of deltas worldwide within the next century (Giosan et al., 2014). Preliminary estimates of deltaic areas prone to be partially or totally submerged with the resulting loss of deltaic and wetland habitats by 2050, are already available (e.g., Ericson et al., 2006). Also, seawater will intrude into deltaic channels, thereby forcing brackish habitats to migrate upstream and inland at the expense of freshwater habitats.

Because deltas house high biological and cultural diversity and because millions of people currently live in deltas, the potential disappearance of deltaic habitats and derived biodiversity, goods, and services is a major concern. Most of the major world deltas host legal figures of environmental and cultural protection where ecosystem conservation and human development attempt to coexist (Supplementary Table 1). Some examples are Biosphere Reserves or Managed Resource Protected Areas, which extend over restricted areas of the Earth's surface and enclose habitats and species that need to be preserved. However, climate change threatens to render these figures ineffective because rising temperatures and sea level will cause irreversible spatial shifting of habitats outside the protection boundaries and/or habitat degradation or replacement inside them such that the original protective effect on biodiversity is lost. In fact, paleoecological records show that under past climate warming, deltaic, and coastal habitats shifted landward or were replaced by 
open water, mountain habitats shifted upward, and temperate habitats shifted poleward. Inhabiting species were forced to move following their habitats if they could not acclimatize; otherwise, their numbers decreased or they became extinct, which resulted in high biodiversity losses (Rull and Vegas-Vilarrúbia, 2006; Ellison, 2008). These range shifts can occur at centennial time scales as a response to rapid climatic changes. In fact, a consistent pattern of latitudinal and altitudinal range displacements has been recorded worldwide during the last century likely caused by the current global warming (Donnelly and Bertness, 2001; Parmesan and Yohe, 2003; Burrows et al., 2011; Bebber et al., 2013; Savage and Vellend, 2014). The issue is that many in situ conservation figures currently protect highly valuable deltaic habitats that might be under water within a few decades, and more awareness and control of such situations is needed. It is urgent to detect "SLR hotspots," determine tipping points at which deltaic habitats would become too adverse to sustain current life, anticipate non-linear ecosystems' responses, and search for natural refuge areas to protect.

The IPCC (2013) recognizes the following three adaptation and mitigation strategies for adapting to SLR in deltaic/coastal areas till 2100: (1) protection of people, property, and infrastructure based on the "hold-the line" approach through "hard" engineering defenses; (2) adapting human activities and removing infrastructures to accommodate the rising sea level; (3) retreating landward and leaving the coastal front. Determining the most suitable alternatives or combination thereof is casedependent and requires sufficient knowledge, careful evaluation, and dynamic adjustment over time.

We propose a fourth, parsimonious strategy that follows the idea of vanishing habitats with SLR, primarily for deltas where millions of people depend directly on deltaic biodiversity, ecosystem services, and natural capital. Unlike the aforementioned adaptive strategies, the one proposed here is preventive and favors deltaic resilience. It consists of discouraging/preventing the further human settlement of deltaic/coastal areas that are seriously threatened by SLR, especially in developing countries. For instance, megadeltas in Asia, are among the most economically dynamic regions in the world and possess important migration powered urban centers. However, despite the flourishing manufacturing and processing development, their economy relies on significantly natural capital and ecosystem services, which in turn rely on highly biodiverse ecosystems and associated habitats structured around sea level and river discharge (Seto, 2011). Therefore, their communities, biodiversity, and infrastructure are at risk of being damaged by current SLR (Schneider et al., 2007).

Further migration to such densely populated and threatened areas will likely produce more stress and decrease resilience in the near future. Moreover, inhabitants of the deltaic areas to be impacted by SLR will very likely migrate to safer and more stable areas within the same delta. It is possible to roughly assess the magnitude of migration by computing the number of people affected on average by SLR only (i.e., without considering storms and surges). Based on the same data and assumptions of Ericson et al. (2006) about SLR impact on humans inhabiting major deltas and land loss, we preliminarily estimate the magnitude of population density increase in 37 major deltas from 2000 to 2050, if population at risk would abandon the area impacted/flooded for each delta and move to neighboring areas (Figure 1). Different scenarios arise: $39.4 \%$ of the deltas would increase population density by more than 100 habitants $/ \mathrm{km}^{2}$, including increases as dramatic as $>1000 \mathrm{hab} . / \mathrm{km}^{2}$ (Nile and Bengal); $26.3 \%$ would increase between 10 and 99 hab. $/ \mathrm{km}^{2}$ (e.g., Mississippi and Rhone) and $36.8 \%$ would increase $<10$ hab. $/ \mathrm{km}^{2}$ (e.g., Orinoco, Lena). Climate change-induced migration is a likely source of conflict in areas receiving migrants, the intensity of which may vary depending on competition for resources, ethnic tension, and distrust (Reuveny, 2007).

Few assessments have concentrated on the economic impact of deltaic/coastal biodiversity and ecosystem loss due to the impacts of SLR in developing countries. Altogether, this impact will become more difficult to manage because less developed countries are less likely to successfully mitigate the impacts of SLR because they lack wealth and expertise (Reuveny, 2007). Discouraging further migration to such vulnerable areas would make sense and decrease future human suffering because the sea level is expected to increase for centuries, even if global warming is palliated (Giosan et al., 2014). A recent study revealed that in megadeltas, migration to urban centers is an outcome of economic policies and incentives, local and destination institutions, government policies to develop small towns, and the geographic concentration of investments (Seto, 2011). These social drivers of migration initiatives should be urgently revised considering the available SLR scenarios and its synergies with other threatening deltaic environments, i.e., weather-related risks and overpopulation. Sustainable development in deltaic areas, if possible, requires policies and programs to help the current deltaic residents adapt to SLR. In this regard, regulating the incoming migration fluxes and providing more conservative development strategies and cautious investments are important preventive measures that will alleviate the long-term social and economic losses.

However, it is worrisome that major world deltas are already in danger of tipping into a "collapsed" state of their social and ecologic systems due to the synergy between anthropogenic pressure and climate change-related stress (Ericson et al., 2006; Renaud et al., 2013). The resulting disruption of biodiversitydependent livelihoods, resource shortages and social tension will likely trigger a counter-flux of "climate migrants" leaving the affected areas (Reuveny, 2007), which will require humanitarian and political responses.

Another insufficiently noted source of concern associated with vanishing deltaic habitats is the demise of ancestral human cultures, including the related losses of cultural diversity, traditional knowledge, and resources. Such cultures are commonly in a unsuccessful process of assimilation into "mainstream" societies, e.g., Bugakwe and Xanekwe at Okavango delta (Botswana), Warao at Orinoco delta (Venezuela), Pokomo, Orma, Somalis, and Warday at Tana delta (Kenya); or even suffering the consequences of habitat destruction on their way of life, as is the case of the Ma'dān or marsh Arabs at Shatt Al-Arab delta (Iraq), after the 2003 war against Iraq (Adriansen, 2004). These cultures have $<10$ individuals/ $\mathrm{km}^{2}$ (IGWIA, 2014) 

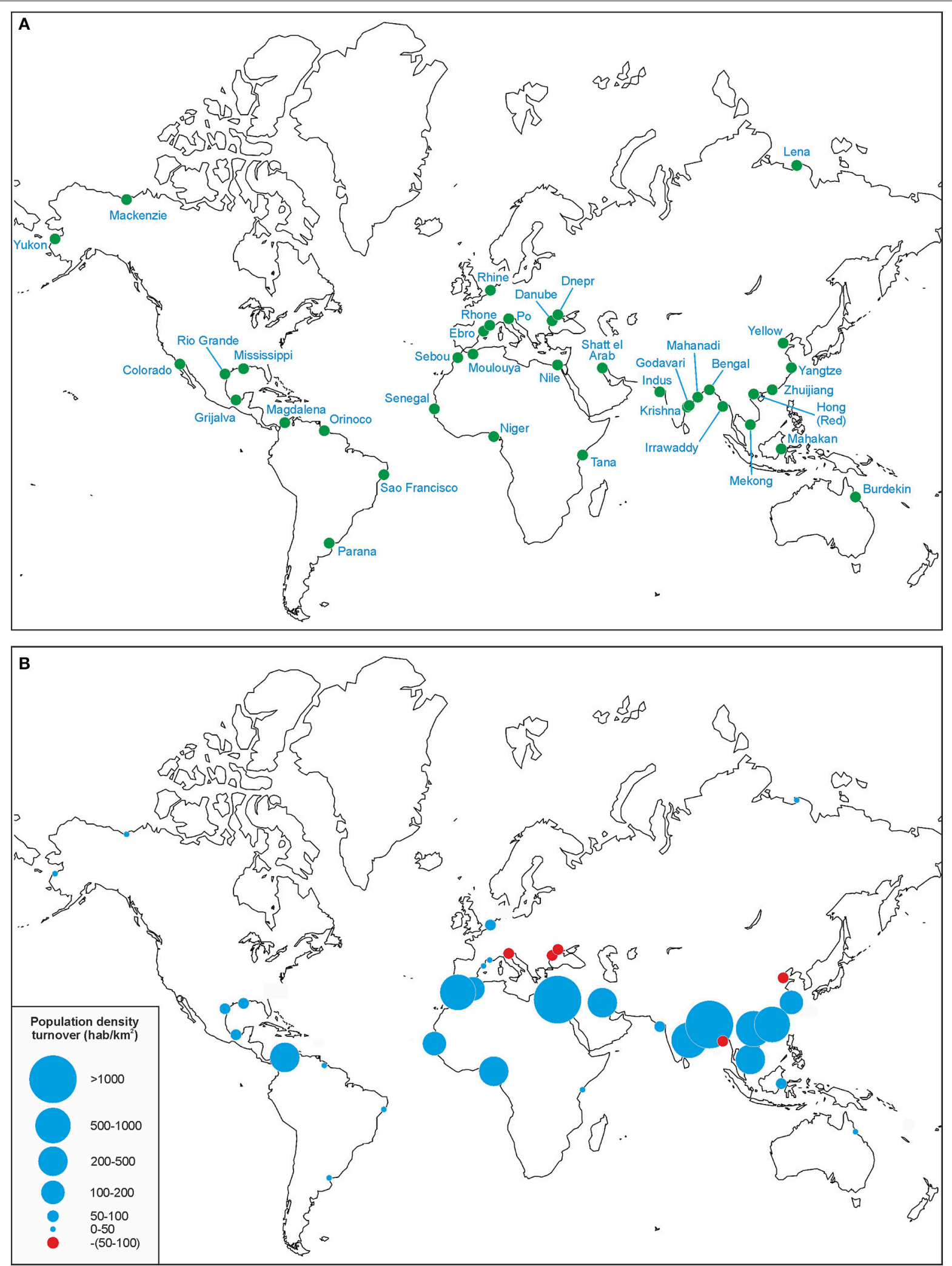

FIGURE 1 | Changes in population density across the major world deltas projected by 2050 under the SLR scenario considered in this paper. (A) Location of the deltas considered. (B) Estimated changes in population density. Blue circles represent density increases and red circles density decreases. Raw data from Ericson et al. (2006). 
so that even a small population decline would represent a steep drop in their population numbers. SLR may hardly impact on these vulnerable populations and threaten their persistence as a culture and their continued existence as a distinctive ethnic group (e.g., Vegas-Vilarrúbia et al., 2015). It cannot be taken for granted that deltaic ethnic groups have acquired experience to successfully confront the impacts of SLR because modern deltas reached their current sea levels 5000-6000 years ago at much slower paces (Stanley and Warne, 1994). The current changes are predicted to occur very rapidly, ultimately producing more or less abrupt shifts and leading to the disappearance of, or significant changes to, traditional habitats, goods, and services. To protect habitats, the ILO's Convention 169 initiatives on "Indigenous and Tribal Peoples in Independent Countries" (IGWIA, 2014) demand the effective protection of indigenous rights of ownership and possession of traditionally owned lands, which would be ineffective if these territories collapse under SLR. Policies and programs to help deltaic inhabitants facing SLR should pay special attention to indigenous people if they are forced to abandon their ancestral territories and should provide suitable territories for their settlement or successful assimilation into mainstream societies.

\section{IN SUMMARY}

Current SLR might be considered a significant extinction force because of its high potential to degrade, reduce, or eliminate deltaic and coastal habitats, thereby promoting huge diversity losses. Nonetheless, the effects of SLR are still too frequently ignored in terms of designing biodiversity conservation strategies or developing urban/rural areas.

SLR represents a serious threat to millions of people living in densely populated deltas.

\section{REFERENCES}

Adriansen, H. K. (2004). What Happened to the Iraqi Marsh Arabs and Their Land? DIIS Working Paper 2004/26. Copenhagen: Danish Institute for International Studies.

Bebber, D. P., Ramotowski, M. A. T., and Gurri, S. J. (2013). Crop pests and pathogens move polewards in a warming world. Nature Clim. Change 3, 985-988. doi: 10.1038/nclimate1990

Burrows, M. T., Schoeman, D. S., Buckley, L. B., Moore, P., Poloczanska, E. S., and Brander, K. M., et al (2011). The pace of shifting climate in marine and terrestrial ecosystems. Science 334, 652-655. doi: 10.1126/science.1210288

Church, J. A., Clark, P. U., Cazenave, A., Gregory, J. M., Jevrejeva, S., Levermann, A., et al. (2013): "Sea level change," in Climate Change 2013: The Physical Science Basis. Contribution of Working Group I to the Fifth Assessment Report of the Intergovernmental Panel on Climate Change, eds T. F. Stocker, D. Qin, G.-K. Plattner, M. Tignor, S. K. Allen, J. Boschung, A. Nauels, Y. Xia, V. Bex, and P.M. Midgley (Cambridge, UK; New York, NY, USA: Cambridge University Press).

Donnelly, J. P., and Bertness, M. D. (2001). Rapid shoreward encroachment of salt marsh cordgrass in response to accelerated sea-level rise. Proc. Natl. Acad. Sci. U.S.A. 98, 14218-14223. doi: 10.1073/pnas.251209298

Ellison, J. C. (2008). Long-term retrospection on mangrove development using sediment cores and pollen analysis: a review. Aquat. Bot. 89, 93-104. doi: 10.1016/j.aquabot.2008.02.007

Ericson, J. P., Vörösmarty, C. J., Dingman, L. S., Ward, L. G., and Meybeck, M. (2006). Effective sea-level rise and deltas: Causes of change and
Almost $40 \%$ of major deltas, most of them already overpopulated, may increase their population density by $>100$ hab./km² (2000-2050).

Most adaptive measures to confront SLR in deltaic habitats will become more expensive and more difficult to execute with continued human growth. Growing populations also increasingly exploit biodiversity goods and services, adding stress to the deltaic ecosystems that strive to acclimatize to SLR. Beyond a certain point, additional pressure would favor their collapse.

To achieve some degree of success, adaptive measures might be reinforced by specific policies and regulations, such as migration control and development restrictions.

Biodiverse and sparsely populated deltas housing ethnic minorities may remain unattended and rely on their own resilience to SLR, whereas wealthy and densely populated deltas will be given priority.

The selection of strategies to adequately address SLR in delta environments should be performed in the context of longterm planning. Because the long term is full of uncertainties, space- and time-specific research efforts should be devoted to address knowledge gaps before information demands become progressively too pressing.

\section{AUTHOR CONTRIBUTIONS}

TV conceived the idea and wrote the paper. VR provided new ideas, participated in writing and made the figures.

\section{SUPPLEMENTARY MATERIAL}

The Supplementary Material for this article can be found online at: http://journal.frontiersin.org/article/10.3389/fevo. 2016.00077

human dimension implications. Glob. Planet. Change 50, 63-82. doi: 10.1016/j.gloplacha.2005.07.004

Giosan, L., Syvitski, J., Constantinescu, S., and Day, J. (2014). Climate change: protect the world's deltas. Nature 516, 31-33. doi: 10.1038/516031a

IGWIA (2014). International Group Work Group for Indigenous Affairs. Available online at http://www.iwgia.org/iwgia/where-we-work- (Accessed December 2014).

IPCC (2013). "Summary for policymakers," in Climate Change 2013; The Physical Science Basis. Contribution of Working Group I to the Fifth Assessment Report of the Intergovernmental Panel on Climate Change, eds T. F. Stocker, D. Qin, G.-K. Plattner, M. Tignor, S. K. Allen, J. Boschung, et al. (Cambridge, UK; New York, NY, USA: Cambridge University Press), 3-29.

Parmesan, C., and Yohe, G. (2003). A globally coherent fingerprint of climate change impacts across natural systems. Nature 421, 37-42. doi: 10.1038 /nature01286

Renaud, F. G., Syvitski, J. P. M., and Sebesvari, Z. (2013). Tipping from the Holocene to the Anthropocene: how threatened are major world deltas? Curr. Opin. Environ. Sustain. 5, 644-654. doi: 10.1016/j.cosust.2013. 11.007

Reuveny, R. (2007). Climate change-induced migration and violent conflict. Polit. Geogr. 26, 656-673. doi: 10.1016/j.polgeo.2007.05.001

Rull, V., and Vegas-Vilarrúbia, T. (2006). Unexpected biodiversity loss under global warming in the neotropical Guayana Highlands: a preliminary appraisal. Glob. Change Biol. 12, 1-9. doi: 10.1111/j.1365-2486.2005. 001080.x 
Savage, J., and Vellend, M. (2014). Elevational shifts, biotic homogenization and time lags in vegetation change during 40 years of climate warming. Ecography 38, 546-555. doi: 10.1111/ecog.01131

Schneider, S. H., Semenov, S., Patwardhan, A., Burton, I., Magadza, C. H. D., Oppenheimer, M., et al. (2007). "Assessing key vulnerabilities and the risk from climate change," in Climate Change (2007): Impacts, Adaptation and Vulnerability. Contribution of Working Group II to the Fourth Assessment Report of the Intergovernmental Panel on Climate Change, eds M. L. Parry, O. F. Canziani, J. P. Palutikof, P. J. van der Linden and C. E. Hanson (Cambridge, UK: Cambridge University Press), 779-810.

Seto, K. C. (2011). Exploring the dynamics of migration to megadelta cities in Asia and Africa: contemporary drivers and future scenarios. Glob. Environ. Change 21, 94-107. doi: 10.1016/j.gloenvcha.2011. 08.005

Stanley, D. J., and Warne, A. G. (1994).Worldwide initiation of Holocene marine deltas by deceleration of sea-level rise. Science 265, 228-231. doi: $10.1126 /$ science. 265.5169 .228
Syvitski, J. P. M., Kettner, A. J., and Overeem, I. (2009). Sinking deltas due to human activities. Nature Geosci. 2, 681-686. doi: 10.1038/ngeo629

Vegas-Vilarrúbia, T., Hernández, E., Rull, V., and Rull-Vegas, E. (2015). The Orinoco megadelta as a conservation target in the face of the ongoing and future sea level rise. Sci. Tot. Environ. 515-516, 129-142. doi: 10.1016/j.scitotenv.2015.01.056

Conflict of Interest Statement: The authors declare that the research was conducted in the absence of any commercial or financial relationships that could be construed as a potential conflict of interest.

Copyright (c) 2016 Vegas-Vilarrúbia and Rull. This is an open-access article distributed under the terms of the Creative Commons Attribution License (CC BY). The use, distribution or reproduction in other forums is permitted, provided the original author(s) or licensor are credited and that the original publication in this journal is cited, in accordance with accepted academic practice. No use, distribution or reproduction is permitted which does not comply with these terms. 